\title{
Loxoscelismo cutáneo
}

\author{
Natacha Hernández Pérez ${ }^{a}$, José M${ }^{a}$ Alonso Gordo ${ }^{b}$ Ángela Fuentes López ${ }^{a}$
}

\author{
${ }^{\text {a }}$ Residente de Medicina Familiar \\ y Comunitaria. Centro de Salud \\ Guadalajara-Sur, Guadalajara, \\ España.

\begin{abstract}
${ }^{\mathrm{b}}$ Médico de Familia. Centro de Salud Guadalajara-Sur, Guadalajara, España.
\end{abstract}

Correspondencia: José $\mathrm{M}^{\mathrm{a}}$ Alonso Gordo, Centro de Salud Guadalajara-Sur, C/ Ferial $n^{\circ} 31$, $1^{\text {a }}$ planta, 19002 - Guadalajara, España. Correo electrónico: jmalonso@sescam.org.

Recibido el 2 de diciembre de 2011.

Aceptado para su publicación el 16 de diciembre de 2011.

\section{RESUMEN}

Las picaduras por artrópodos son muy frecuentes en nuestro medio. Las más habituales son producidas por insectos, miriápodos y arácnidos (arañas y escorpiones). El veneno de la araña Loxosceles tiene propiedades necrotizantes, hemolíticas, vasculíticas y coagulantes, y el cuadro puede presentarse bajo dos formas bien definidas: Loxoscelismo cutáneo y Loxoscelismo cutáneo-visceral o sistémico, menos frecuente. En la piel puede provocar graves alteraciones vasculares, con áreas de vasoconstricción y otras de hemorragias que conllevan de inmediato a la isquemia local y a veces a la placa gangrenosa.

Presentamos el caso de una mujer de 36 años que acude con una lesión en el miembro inferior izquierdo, refiriendo que le ha picado una araña en su domicilio. A los pocos días le aparece una placa necrótica de color violáceo, con una ulceración de evolución tórpida. Durante el seguimiento de la lesión aparecen en dos ocasiones lesiones similares, refiriendo nuevas picaduras de araña. Palabras Clave: Mordeduras y Picaduras, Arañas.

\section{ABSTRACT}

\section{Cutaneous Loxoscelism}

Arthropod bites are very common in our surroundings; they are most often caused by insects, millipedes and arachnids (spiders and scorpions). The venom of the Loxosceles genus of spiders has necrotizing, hemolytic, vasculitic and coagulant properties. The clinical picture may present itself in two distinct forms: cutaneous Loxoscelism or, less frequently, cutaneous-visceral or systemic Loxoscelism. In the skin, the venom can cause severe vascular changes, with areas of vasoconstriction and other areas of bleeding that rapidly lead to local ischemia and sometimes to a gangrenous plaque.

We present the case of a 36-year-old woman with a left lower limb lesion, who reported having been bitten by a spider in her home. A few days later, she developed a purplish necrotic plaque with slow growing ulceration. While monitoring the lesion, the patient received two new spider bites, similar in appearance to the first one.

Key words: Bites and Stings, Spiders.

Un resumen de este trabajo fue presentado en las VI Jornadas Autonómicas de Residentes de Medicina de Familia y Comunitaria celebradas en Toledo los días 21 y 22 de Octubre de 2011.

\section{INTRODUCCIÓN}

Las picaduras por artrópodos son muy frecuentes en nuestro medio. Las más habituales son producidas por los insectos (moscas, mosquitos, pulgas, abejas, avispas), algunos miriápodos (ciempiés, escolopendra) y los arácnidos (arañas y escorpiones) 1 . La picadura por Loxosceles ocupa un lugar de importancia dentro de las picaduras de arañas en el mundo, después de la producida por Latrodectus o viuda negra. En nuestro país pueden producirse picaduras por arañas venenosas del tipo Loxosceles rufescens o araña de rincón, Latrodectus tridecimguttatus o viuda negra y Lycosa tarantula o tarántula ${ }^{2}$. La picadura por Loxosceles siempre es accidental y puede dar lugar a una necrosis muy extensa con formación de úlceras de difícil cicatrización y en ocasiones produce lesiones deformantes que requieren una intervención quirúrgica ${ }^{2,3}$. Las Loxosceles son arañas de actividad principalmente nocturna, se reproducen fundamentalmente en la época de verano, se alimentan de pequeños insectos, no suelen ser agresivas y sólo atacan si se sienten amenazadas y no existe alternativa 
de huida. Las picaduras se producen sobre todo en los miembros superiores o inferiores, cara, tórax y cuello. A pesar de que en España y en otras zonas del mediterráneo existen algunos casos registrados por la picadura de esta araña, en su variedad de Loxosceles rufescens, las formas de Loxoscelismo más graves (por L. laeta y $L$. reclusa) son más típicas de los países de África y América del Sur fundamentalmente $e^{2,3,5}$.

\section{OBSERVACIONES CLÍNICAS}

Paciente de 36 años, administrativa, sin antecedentes de salud importantes, que acude a Urgencias de Atención Primaria por lesión inflamatoria en cara lateral externa de la pierna izquierda de unos 10 $\mathrm{cm}$ de diámetro tras la picadura de una araña. Tras una semana de tratamiento con antiinflamatorios y antihistamínicos, le aparece una ulceración con escara en dicha zona, aumento del dolor local, fiebre de $38^{\circ}$ y malestar general, acudiendo al Servicio de Urgencias en dos ocasiones. La analítica sólo demuestra aumento de PCR (13mg/l). Se inicia tratamiento con corticoides, amoxicilinaclavulánico, metamizol y antihistamínicos, y se recomienda mantener la escara por el riesgo de posible diseminación del tóxico.

A los 15 días de la picadura inicial acude a la consulta de Atención Primaria, observándose una lesión inflamatoria en el $1 / 3$ medio de la pierna izquierda con una placa necrótica de unos $3 \mathrm{~cm}$ de diámetro, de bordes irregulares y color violáceo, además de una edematización en piel circundante. Se realiza una cura con apósito graso antibiótico y al día siguiente se retira la escara persistiendo una ulcera de unos $2 \mathrm{~cm}$ poco profunda con fondo oscuro, con inflamación perilesional, sin edema de miembro, linfangitis ni supuración. Posteriormente se realizan curas locales y aplicación de apósitos hidrocelulares y absorbentes, manteniendo el tratamiento oral con antihistamínicos, antibióticos y antiinflamatorios.

La ulceración mejora progresivamente y pocos días después consulta por una nueva picadura más leve en la misma pierna y posteriormente por una tercera con características similares a la primera, iniciándose nuevo ciclo de tratamiento antibiótico, corticoideo, antihistamínico y antiinflamatorio. Transcurrido un mes y medio aproximadamente de la primera picadura, las lesiones han desaparecido y la paciente se encuentra asintomática

\section{COMENTARIOS}

Las picaduras por arañas pueden ser relativamente frecuentes, pero en muchas ocasiones pasan prácticamente desapercibidas 0 es imposible confirmar con exactitud que la picadura ha sido producida por ellas. Asimismo puede ser difícil confirmar a qué género pertenece el agente específico. Las más frecuentes en el área mediterránea son la Loxosceles rufescens, como en el caso que nos ocupa, Latrodectus tredecinguttatus (viuda negra), con efectos neurotóxicos, y Lycosa tarentula (tarántula), que produce una lesión necrótica superficial, únicamente epidérmica ${ }^{1}$.

A la Loxosceles también se le conoce como araña asesina, reclusa, de violín o araña de rincón. Tiene color marrón y la forma del cuerpo presenta unas rayas más oscuras, recordando la forma de un violín. Una hembra adulta puede llegar a medir con las patas extendidas hasta $30 \mathrm{~mm}$. Presenta 4 pares de ojos (en lugar de dos) y las podemos encontrar detrás de cuadros, espejos, muebles cercanos a la pared (es llamada araña del rincón), persianas, etc. ${ }^{3,5}$.

En nuestro caso la paciente pudo reconocer y fotografiar el tipo de araña en las sucesivas picaduras, identificando además la localización del nido de los arácnidos: los conductos del aire acondicionado de una vivienda recientemente habitada.

El loxoscelismo comienza con una lesión local en el sitio de la picadura, inicialmente eritematoedematosa, posteriormente en forma de mácula violácea equimótica a la que siguen pequeñas vesículas ${ }^{4,5}$ $y$, finalmente, una costra o escara necrótica que se desprende en 3-6 semanas, descubriendo una úlcera de profundidad variable ${ }^{2,3,5}$. Aun habiendo una zona central hipoestésica, la zona afectada es muy dolorosa, y en ocasiones se produce un cuadro general con fiebre, cefalea, mialgias, fracaso renal o manifestaciones por trastornos de la coagulación (forma cutáneo visceral). En raras ocasiones las lesiones locales son tan intensas que requieren desbridamiento quirúrgico e injertos cutáneos ${ }^{2,3}$, habiéndose publicado varios casos de muerte en Chile ${ }^{5}$.

Lo localización de las mordeduras suele ser extremidades superiores o inferiores, cara, cuello y tórax. Algunas formas en manos han dado lugar a graves lesiones necrotizantes ${ }^{2} y$ existen también casos de mordedura en párpados ${ }^{4}$. 
La base fisiopatológica del cuadro clínico parece radicar en el efecto de diversas enzimas, como la esfingomielinasa, que actúa a nivel vascular ${ }^{3,5}$, dando lugar a edema, adelgazamiento del endotelio vascular, acumulación de células inflamatorias, vasodilatación, coagulación intravascular, degeneración de las paredes vasculares y hemorragias (vasculitis). En los cuadros sistémicos es frecuente la hemolisis con manifestaciones viscerales, producida por la modificación de los componentes de la membrana eritrocitaria y vascular ${ }^{5}$.

No existe ningún examen complementario que confirme el diagnóstico, siendo éste eminentemente clínico ${ }^{2}$. El diagnóstico diferencial en el caso del loxoscelismo cutáneo debe hacerse con picaduras de otros insectos y arácnidos, herpes simple, herpes zoster, erisipela, carbunco, lupus eritematoso cutáneo, edema angioneurótico y vasculitis ${ }^{2,5}$.

El tratamiento no está basado en un criterio unánime, debiendo tenerse en cuenta diversos factores: tiempo transcurrido entre el accidente y la consulta, las manifestaciones clínicas (cutáneas o sistémicas), etapa evolutiva (pre-necrótica, ulcerosa) y la aparición de complicaciones. El tratamiento recomendado para las formas cutáneas es el siguiente: reposo, aplicación de frío local

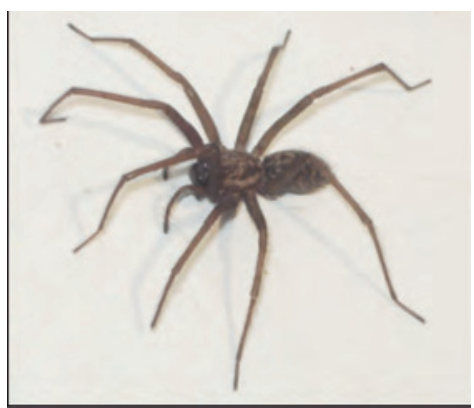

Figura 1. "La Araña del Rincón". (medidas suficientes para la mayoría de los casos en nuestro medio), antihistamínicos, corticoides sistémicos, antibióticos, vacuna antitetánica y analgésicos $^{1-3,5}$. No se recomiendan medidas agresivas iniciales (torniquetes, succiones, escarectomías precoces, etc.), que pueden aumentar la morbilidad ${ }^{2,3}$. En los casos más graves, y en algunos países de Sudamérica, se ha utilizado dapsona y suero antiloxosceles, pero los numerosos efectos secundarios, dudosa eficacia y la habitual escasa gravedad de los cuadros en nuestros medios los posicionan como un recurso terapéutico poco habitual ${ }^{1-3}$.

Para la prevención se recomienda realizar limpiezas periódicas de rincones y zonas ocultas donde se puedan esconder las arañas, revisar lo ropa tendida o colgada antes de utilizarla y no colocar las camas en contacto directo con las paredes ${ }^{5}$.

Como conclusión, aunque las picaduras de artrópodos pueden ser frecuentes en nuestro medio y suelen tener poca trascendencia clínica en la mayor parte de los casos, debemos considerar esta posibilidad en pacientes que debuten con una lesión sugestiva de picadura, no identificación del agente causal y evolución más tórpida de lo esperable.

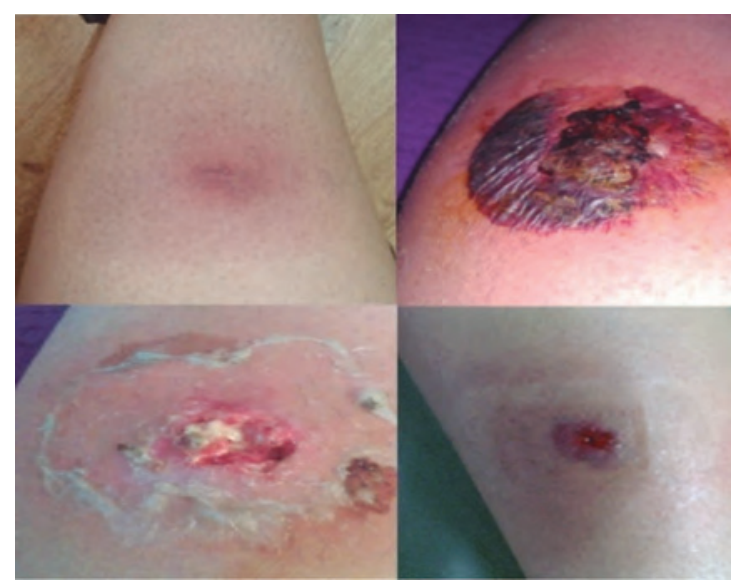

Figura 2. Evolución de las lesiones.

4. Portilla Cuenca J, Maresca Quintero M, Hoyos Sanabria B, García Benito JI, Vélez Medina J. Lesión necrótica palpebral por picadura de araña. Arch Soc Esp Oftalmol. 2005; 80:105-8.

5. Schenone H. Cuadros tóxicos producidos por mordedura de araña en Chile. Rev Méd Chile. 2003; 131:437-44. 